Servicio de Radiología Clínica

Avansalud. Santiago, Chile.

Recibido el 29 de agosto de 2016, aceptado el 21 de marzo de 2017.

Correspondencia a: Dr. Roberto Miranda Servicio de Radiología Clínica Avansalud, Santiago, Chile. rmradiologia@gmail.com

\section{Ruptura pieloureteral espontánea bilateral durante un urotac. Caso clínico}

\author{
ROBERTO MIRANDA, PATRICIO LATORRE, RODRIGO RAURICH
}

\section{Bilateral spontaneous renal pelvis rupture during a computed tomography. Report of one case}

\begin{abstract}
Spontaneous rupture of the urinary excretory system is a rare condition. It is mainly associated with obstruction of the excretory system and is usually unilateral. We report a 58 years old male who, during the performance of a computed tomography of the urinary system, felt an intense lumbar pain. A bilateral rupture at the level of the fornix was found. The patient had an uneventful evolution thereafter. Fifteen days later a new computed tomography showed indemnity of the urinary excretory system.
\end{abstract}

(Rev Med Chile 2017; 145: 544-548)

Key words: Extravasation of Diagnostic and Therapeutic Materials; Kidney pelvis; Rupture; Rupture, Spontaneous; Tomography, Xray Computed.
L a ruptura espontánea del sistema excretor pielocaliciario es una entidad poco frecuente que puede tener importante repercusión clínica. La casi totalidad se asocia a obstrucción del sistema excretor, principalmente litiasis y causas menos frecuentes como estenosis, trauma, tumor o enfermedad del tejido conectivo ${ }^{1-5}$. Desde las ya clásicas descripciones de pielografías de eliminación y tomografía computada (TC) ${ }^{2-4}$, el diagnóstico por imágenes es esencial para determinar su ubicación, cuantía, presencia de complicaciones y evolución. Reportamos un caso insólito de ruptura espontánea pieloureteral bilateral vivida durante la realización de una tomografía computada (TC), en un paciente sin antecedentes mórbidos y sin patología obstructiva del sistema excretor.

\section{Caso clínico}

Paciente varón de 58 años, enviado al Servicio de Imágenes por el urólogo para un urotac con diagnóstico de micro hematuria, sin antecedentes mórbidos personales ni familiares de importancia conocidos. Tampoco tenía antecedentes de alergias ni reacciones previas al medio de contraste. Posterior a la administración de contraste por vía endovenosa, el paciente refirió intenso dolor lumbar. Se suspendió el examen y fue llevado al servicio de urgencia para su evaluación. Se confirmó el dolor lumbar, una leve taquicardia, eupneico, con una presión arterial normal. Fue tratado con analgésicos por vía endovenosa y el dolor cedió en forma importante. También orinó normalmente sin hematuria macroscópica. Se tomó una creatininemia de $1,15 \mathrm{mgr} / \mathrm{dl}$.

Como la urotac es una TC orientada principalmente a la evaluación del riñón y las vías urinarias, es necesario hacer primero el estudio sin contraste, luego una fase a los 70 segundos para realzar el parénquima renal $y$, una fase tardía para evaluar el sistema excretor. Por esto, nuestro paciente fue llevado nuevamente a tomografía para realizarla fase de eliminación del examen. En ese instante se 

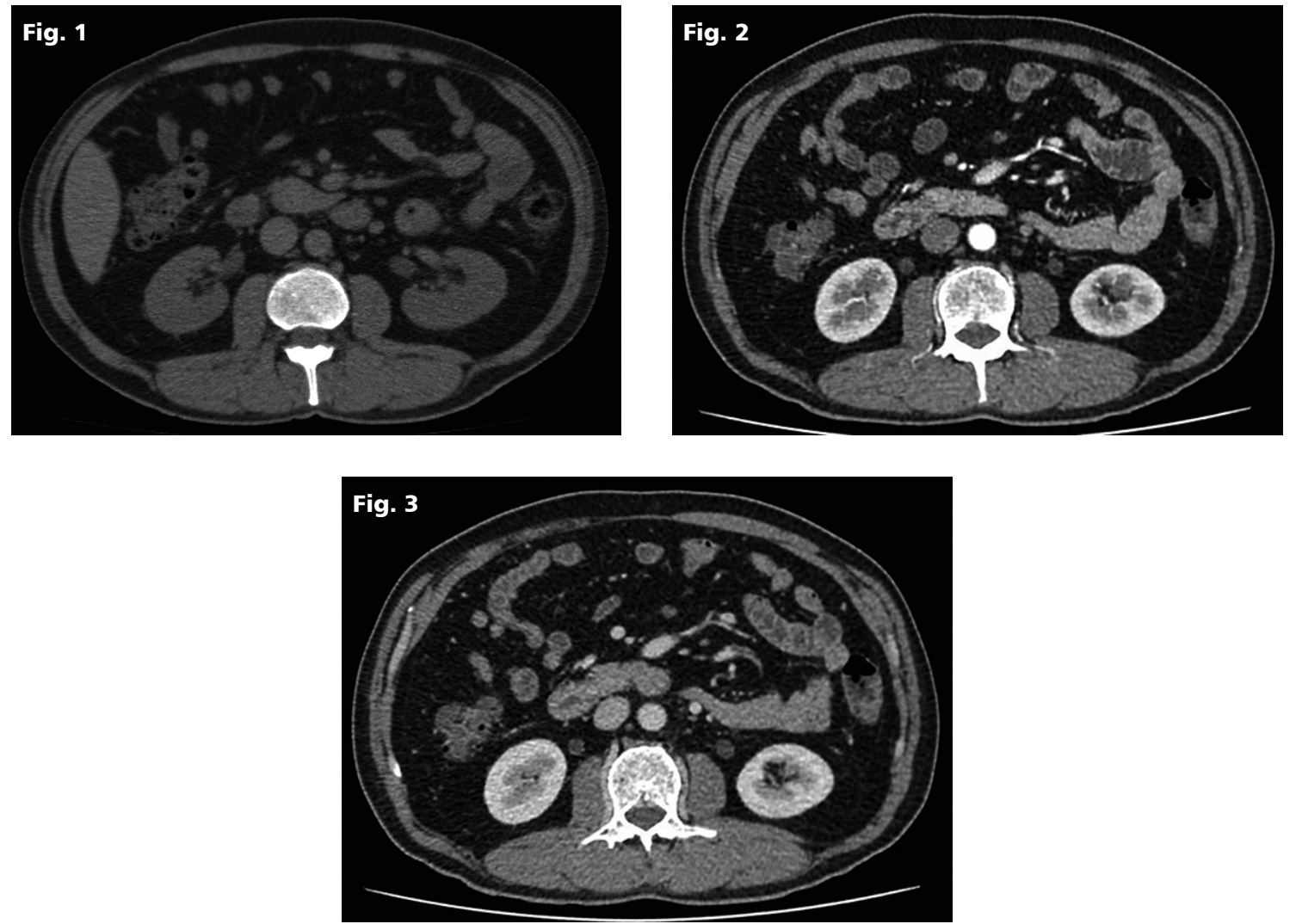

Figuras 1, 2 y 3. Imágenes axiales sin contraste endovenoso, en fase arterial y en fase venosa de aspecto normal, sin cálculos calcificados ni dilatación.

comprobó la ruptura bilateral del sistema excretor. Fue dejado hospitalizado para su observación.

El urotac era normal hasta la fase venosa del estudio (Figuras 1, 2 y 3 ). Los pedículos vasculares y los uréteres no mostraban alteraciones. Sin embargo, en la fase de eliminación tomada después que el paciente vuelve de ser tratado por su dolor lumbar agudo, mostró escape del contraste desde el sistema excretor hacia el retroperitoneo con formación de moderados urinomas por ruptura bilateral a nivel de las uniones pieloureterales. No se observó hidronefrosis y ambos uréteres eran de calibre normal hacia distal. Tampoco se identificó cálculos calcificados. La vejiga de paredes finas, con uniones uréterovesicales libres. La próstata de tamaño normal (Figuras 4, 5, 6 y 7).

En el control a las $24 \mathrm{~h}$ el paciente estaba hemodinámicamente estable, sin dolor, con un hematocrito de 44,8 y una hemoglobina de 15,4 , VHS de 2, leucocitos 12.000 con $86 \%$ segmentados y $0 \%$ de baciliformes. El examen de orina era normal, con 8-10 eritrocitos por campo. La creatinina de $0,75 \mathrm{mgr} / \mathrm{dl}$. Fue dado de alta con control ambulatorio con su urólogo.

El paciente se controló a los 15 días. Se encontraba en buenas condiciones y sin dificultad para orinar. Se realizó un pielotac que mostró ambos riñones morfológicamente normales, sin dilatación de los sistemas excretores ni cálculos y con reabsorción total del contraste extravasado hacia el retroperitoneo. El sedimento urinario era normal, con 4 a 6 eritrocitos $\mathrm{x}$ campo y 0 a 2 leucocitos $\mathrm{x}$ campo, sin cristales. La creatininemia fue de 0,82 mgr/dl (Figuras 8 y 9 ). 

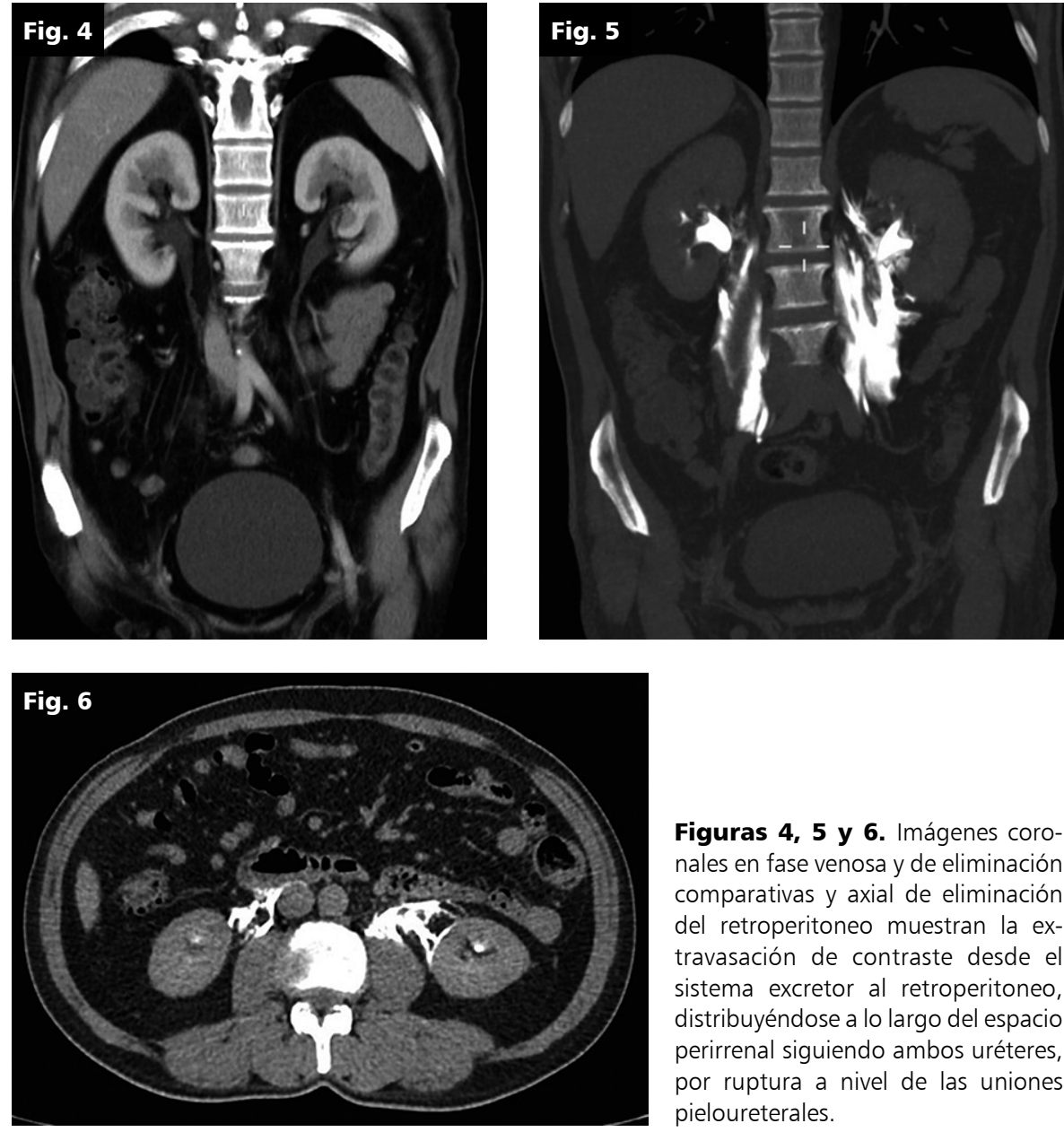

Figuras 4, 5 y 6. Imágenes coronales en fase venosa y de eliminación comparativas y axial de eliminación del retroperitoneo muestran la extravasación de contraste desde el sistema excretor al retroperitoneo, distribuyéndose a lo largo del espacio perirrenal siguiendo ambos uréteres, por ruptura a nivel de las uniones pieloureterales.

\section{Discusión}

La ruptura espontánea del sistema excretor urinario, es una patología infrecuente y se define como una extravasación de orina hacia el tejido perirrenal y retroperitoneo en ausencia de inflamación, trauma, instrumentación previa, cirugía o enfermedad renal conocida ${ }^{1,2,5,6}$. El sitio de ruptura puede estar entre los fórnix de los cálices hasta la uretra. La localización más frecuente es a nivel de los fórnix punto de mayor debilidad al aumento de presión intraluminal.

La ruptura espontánea del sistema excretor renal se conoce desde los trabajos de Albarrán en 1895 y demostradas con pielografías de eliminación por Bonk en 1966 2,3. Todos los trabajos reportan su asociación con patología obstructiva que aumenta significativamente la presión intraluminal, lo más frecuentemente secundario a una litiasis impactada ${ }^{6,7}$. En la gran mayoría de los casos es unilateral en relación al lado obstruido. Causas menos frecuentes son tumores, embarazo, valvas uretrales posteriores, fibrosis retroperitoneal ${ }^{8,9,10,11,12}$. Se han reportado también algunos casos en asociación con periarteritis nodosa, dermatomiositis y lupus?.

Clínicamente se manifiesta por dolor lumbar repentino e intenso, simulando a veces un abdomen agudo, con nauseas y vómitos como un cólico renal, o incluso simulando una colecistitis aguda o una apendicitis ${ }^{9-11}$.

La ruptura bilateral espontánea es aún menos frecuente y, hemos encontrado sólo 1 caso reportadoen la literatura, de ruptura bilateral sin una 


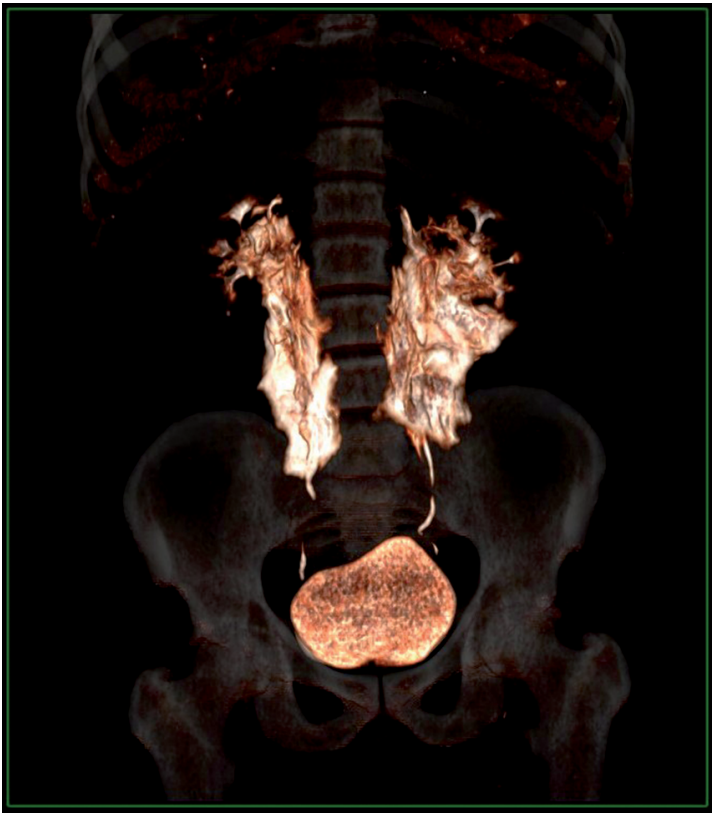

Figura 7. Corresponde a una reconstrucción tridimensional del sistema excretor y las colecciones retroperitoneales, con ambos uréteres de calibre normal y la vejiga de morfología conservada.

aparente obstrucción ${ }^{13}$. El aumento de la presión intraluminal del sistema excretor sobre los 20-75 $\mathrm{mmHg}$, es el factor determinante ${ }^{11}$, junto a una posible menor "compliance" del sistema ${ }^{14}$.

El diagnóstico debe ser precoz para evitar complicaciones como sangramiento o infección. Además, el diagnóstico diferencial puede incluir otras causas de abdomen agudo. El uso precoz de la TC nos dará el diagnóstico ${ }^{3,13}$. En el tratamiento es vital el reposo y control clínico en las primeras 24 h. Según cada caso y evolución, se pueden realizar nefrostomías percutáneas, instalación de catéteres pigtail e incluso se reportan casos que terminan en nefrectomía ${ }^{12,13}$.

En nuestro paciente en ausencia de un factor obstructivo mecánico (cálculo o tumor), la hidratación y la distensión vesical pudieron tener un rol al aumentar la presión intraluminal de los sistemas excretores lo que provocó la ruptura. El diagnóstico precoz y el tratamiento oportuno, favorecieron su rápida recuperación.

\section{Conclusión}

Se presenta un caso de ruptura pieloureteral
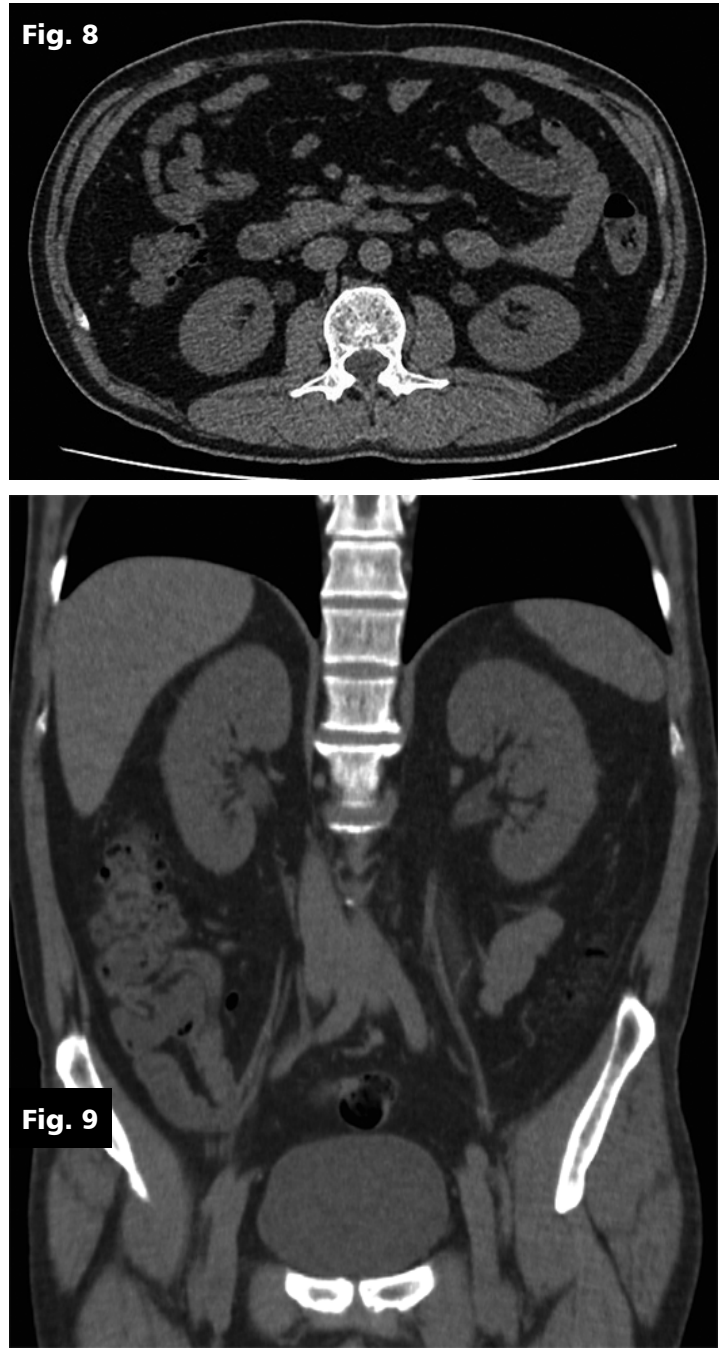

Figuras 8 y 9. Imágenes en los planos axial y coronal del control a los 15 días. Riñones de morfología normal, sin hidronefrosis y regresión total del contraste extravasado.

bilateral espontánea, sin una causa obstructiva, durante la realización de una TC contrastada de abdomen. Es una patología infrecuente, con pocos casos reportados. La mayoría se asocia a patología obstructiva. En nuestro caso, el diagnóstico y tratamiento precoz permitieron una evolución sin complicaciones con recuperación completa.

Creemos que el aumento exponencial del uso de la TC contrastada en diferentes patologías, nos obliga a conocer posibles complicaciones no esperadas, como el de esta presentación. 


\section{Referencias}

1. Bonk J, Basch R, Cheris D. Spontaneous ruptura of the renal pelvis. AJR Am J Roentgenol 1966; 98: 54-62.

2. Bernardino M, Clennan B. High dose urography: incidence and relationship to spontaneous peripelvic extravasation. AJR Am J Roentgenol 1976; 127: 3736.

3. Milty H. CT for diagnosis and management of urinary extravasation. AJR Am J Roentgenol 1980; 134: 497501.

4. Kosehan D, Akin K, Topeu A, Koktener A, Cakir B, Teksam M. Spontaneous urinary extravasation: detection rate with 64-row multidetector computed tomography in patients presenting with acute abdomen. Emerg Radiol 2013; 20: 273-7.

5. Koktener A, Unal D, Dilmen G, Koc A. Spontaneous rupture of the renal pelvis caused by calculus: a case report. The Journal of Emergency Medicine 2007; 33: 127-9.

6. Reyes Figueroa A, Borque A, Gil Martínez P, Fantova A, Gil M. Extravasación urinaria renal espontánea. Revista Chilena de Urología 2014; 79: 51-3.

7. Bolat D, Zumrutbas AE, Baser A, Tuncay L. Sponta- neous ureteral ruptura in a patient with polyarteritis nodosa. Int Urol Nephhrol 2016; 48: 223-4.

8. Ikeda S, Ishikawa M, Kato T. Spontaneous ureteral rupture during concurrent chemoradiotherapy in a woman with uterine cervical cancer. Gynecologic Oncology Reports 2015; 13: 18-9.

9. Chu Y-C, et al. Spontaneous ureteral rupture. Formosan Journal of Surgery 2016; In Press; 10: 1-3.

10. Pampana E, Altobelli S, Morini M, Ricci A, D’Onofrio $\mathrm{S}$, Simonetti G. Spontaneous ureteral rupture diagnosis and treatment. Hindawi Publishing Corporation Case Reports in Radiology 2013; 2013: 1-4.

11. Sierra E, García F. Ruptura espontánea de la pelvis renal secundaria a litiasis ureteral: reporte de un caso y revisión de la literatura. Arch Esp Urol 2011; 64: 640-2.

12. Choi SK, Lee S, Kim S, Kim TG, Yoo KH, Min GE, Lee HL. A rare case of upper ureter rupture: ureteral perforation caused by urinary retention. Korean J Urology 2012; 53: 131-3.

13. Chien JCW, Chang PY, Chan P. Bilateral spontaneous peripelvic urinary extravasation. Kidney International 2014; 86: 448.

14. Gershman B, Kulkarni N, Sahani D, Eisner H. Causes of renal forniceal ruptura. BJUI 2011; 108: 1909-12. 